\title{
Eski Uygurca Kelimelerin Çince Karakterlerle Yazımında Ünsüz Türemesi Olayı
}

\author{
DR. ÖĞR. ÜYESİ HÜSEYİN YILDIZ
}

Öz

Türklerle ilgili en eski kaynaklardaki veriler, Çinlilere ait olup, eski Türkçe kelime ve terimlerle ilgili ancak Çin yıllıklarındaki şekillerinden hareketle fikir yürütülebilmektedir. Çin kaynaklarında Çin imlasıyla geçen kelimelerin Türkçede aslında nasıl olduğunun kesin olarak bilinememesi, Türkoloji'nin önemli problemlerinden biridir. Problemin çözülebilmesi için Türkçe kelimelerin Çincedeki telaffuzlarından yola çıkılarak, çeşitli analizlere ulaşmak ve çeşitli denklikler kurmak mümkün olabilir. Bu konudaki çalışmalara katkıda bulunabilecek eserlerin başında Uygurca-Çince İdikut Sözlüğü adıyla kitaplaştırılan ve XIV. yüzyılda Ming Hanedanı Tercüme Odası tarafından hazırlanan sözlük gelir.

Sözlügün yazımı Ming sülalesinin ilk imparatoru Chu Yüan-chang'in emriyle tercümanlar odası kurularak, Hu-i-i-yü (Çin dilleri ile beraber diğer dillerin karşılaştırmalı sözlüğü) ile beraber 1382 yılında başlatılmıştır. Eserin Pekin'de dört, Japonya'da dört, Avrupa'da yedi nüshası bulunup, sözlük üzerinde Amiot, Klaproth, Ligeti, Hu Chên-hua ve Huang Jun-hua, Paul Pelliot, F. K. Müller ve Mağfiret Kemal Yunusoğlu çalışmıştır. Yunusoğlu'nun çalışması sözlüğün nüshalarının karşılaştırmalı bir yayınıdır. Sözlükteki Eski Uygurca malzemeden hareketle imla, ses, şekil, söz varlığı incelemeleri yapılan eserde açıklamalar, metin ve dizin bölümleri de yer almakta; yukarıda bahsedilen probleme yönelik bir bölüme yer verilmemektedir. Bu çalışmada Yunusoğlu neşrindeki Eski Uygurca kelimelerin Çincedeki imlası esas alınmak suretiyle denkliklere dayalı bir veri tabanı oluşturulmuş; ardından da bu denklikler esaslı ses olayları tespit edilmiştir. Bu çalışma, işte bu ses olaylarından birini, ünsüz düşmesi hadisesini ele almakta ve Türkçe kelimelerin Çincede söylenirken ne tür değişikliklere uğradığını örneklerle göstermektedir.

Anahtar sözcükler: Eski Uygurca, Çince, İdikut Sözlüğü, ses bilgisi, denklikler, ünsüz türemesi.

\section{THE EVENT OF PROSTHESIS IN OLD UIGHUR WORDS WRITTEN WITH CHINESE SPELLING}

\section{Abstract}

The data in the oldest sources about the Turks belong to the Chinese, for this reason, the ideas related to oldest Turkish words and terms can be interpreted based on the figures

\footnotetext{
* Ordu Üniversitesi, Fen Edebiyat Fakültesi, Türk Dili ve Edebiyatı Bölümü, turkbilimci@gmail.com, orcid.org/0000-0002-8055-7946

Gönderim tarihi: 30.03.2019

Kabul tarihi: 12.06 .2019
} 
in Chinese annual. One of the important problems of Turcology is that the obscurity of how the words written with Chinese spelling in Chinese sources are actually in Turkish. In order to solve the problem, it may be possible to reach various analyzes and to establish various equivalents based on the pronunciations of Turkish words in Chinese. The book entitled with Uighur-Chinese Idikut Dictionary is prepared by the Ming Dynasty Translation Room in 15th century and it is one of the principal works that can contribute to the studies on this subject.

The writing of the dictionary was initiated in 1382 together with the Hu-i-iu (a comparative dictionary of Chinese and other languages) by the chamber of interpreters established with the order of Chu Yüan-chang, the first emperor of the Ming Dynasty. The work has four copies in Beijing, four in Japan and seven in Europe and Amiot, Klaproth, Ligeti, Hu Chên-hua and Huang Jun-hua, Paul Pelliot, F. K. Müller and Mağfiret Kemal Yunusoğlu has worked on it. Yunusoglu's work is a comparative publication of dictionary's copies. In the text that has various examinations about spelling, sound, form, vocabulary with reference to the Old Uighur material, there are explanations, text and index sections, but not a section for aforementioned problem. In this study, a database based on equivalences was created depending on Chinese spelling of Old Uighur words in Yunusoğlu's work; and then the sound events based on these equivalences were determined. This study deals with one of these vocal phenomena, the consonant fall and shows the examples of the changes in Turkish words in Chinese pronunciation.

Keywords: Old Uighur, Chinese, Idikut Dictionary, phonetics, equivalents, prosthesis.

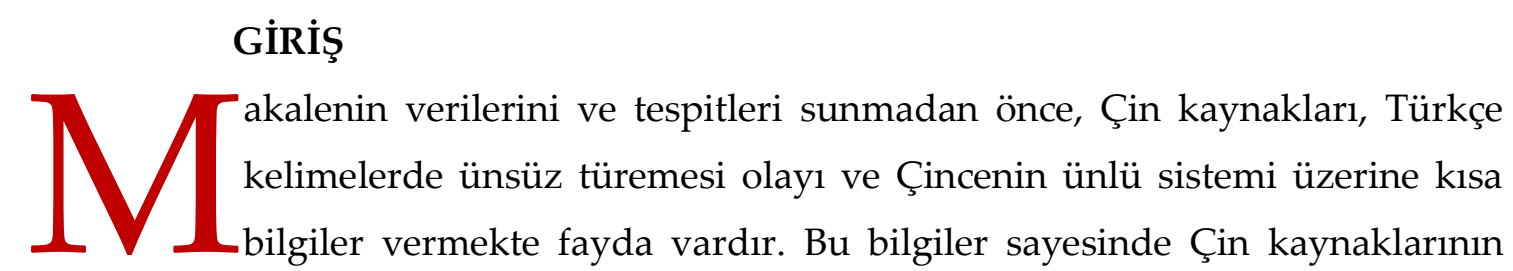
Türkler için önemi daha iyi kavranacak, Türkçe kelimelerde görülen ünsüz türemesi ve Çince ünlü sistemi hakkında bilgi edinilerek Çince kaynaklardaki Türkçe kelimelerin özgün biçimlerine yönelik tespitleri anlamak kolaylaştırılacaktır.

\section{1. ÇİN KAYNAKLARINA DAİR}

Türklerle ilgili en eski kaynaklarla ilgili bir kısım veriler, Çinlilere ait olup, Türkçe kelimelerin, Çin yıllıklarındaki şekillerinden hareketle, özgün biçimleri hakkında fikir yürütülebilmektedir. Eski Türk devletlerinden Hunlarla ilgili pek çok terim ve özel adların Çin kaynaklarındaki yazımlarından hareketle adlandırılması ve literatürde bu şekilde yer alması bu duruma örnek olarak gösterilebilir. 
Çin kaynaklarında Çin yazı sistemiyle yazılan Türkçe kelimelerin Türkçede aslında nasıl olduğunun kesin olarak bilinememesi, Türkolojinin önemli problemlerinden biridir. Problemin çözülebilmesi için Türkçe kelimelerin Çincedeki telaffuzlarından yola çıkılıp listeler oluşturarak çeşitli analizlere ulaşmak ve bu analizlere bağlı olarak çeşitli denklikler kurmak mümkün olabilir.

Çin tarihine bakıldığında, 907'de Tang Hanedanının yıkılmasını takiben Çin'e 500 yıla yakın Çince dışında Altay dilleri konuşan Moğol, Mançu gibi halkların hükmettiği (Fidan, 2011a, s. 6) görülür. 1368-1648 yılları arasında hüküm süren Ming Hanedanı döneminde ise Çin; Doğu Asya'nın askeri, siyasi ve kültürel merkezi haline gelmiştir (Fidan, 2011b, s. 27). Bu hanedan dönemi boyunca Türklerle de ilişkide olan Çin, çeşitli çalışmalarla bu durumu kayıt altına almıştır.

Çin'in kayıt altına aldığı yıllık, seyahatname gibi metinler arasında sözlüklerin de yer alması diller arası ilişkileri göstermesi bakımından ayrıca önem arz etmektedir. Çince karakterlerle yazılan kelimelerin Türkçede doğru tespitine yönelik çalışmalara katkıda bulunabilecek eserlerin başında Mağfiret Kemal Yunusoğlu tarafından 2012 yılında UygurcaÇince Idikut Sözlüğü adıyla kitaplaştırılan ve XIV. yüzyılda Ming Hanedanı Tercüme Odası tarafından hazırlanan sözlük gelmektedir. Sözlüğün yazımı, Ming sülalesinin ilk imparatoru Chu Yüan-chang'in emriyle tercümanlar odası kurularak, Hu-i-i-yü (Çin dilleri ile beraber diğer dillerin karşılaştırmalı sözlüğü) ile beraber 1382 yılında başlatılmıştır. Eserin Pekin'de dört, Japonya'da dört, Avrupa'da yedi nüshası bulunup, sözlük üzerinde Amiot, Klaproth, Ligeti, Hu Chên-hua ve Huang Jun-hua, Paul Pelliot, F. K. Müller ve Mağfiret Kemal Yunusoğlu çalışmıştır. Yunusoğlu'nun çalışması sözlüğün nüshalarının karşılaştırmalı bir yayınıdır.

Sözlükteki Eski Uygurca malzemeden hareketle imla, ses, şekil, söz varlığ incelemeleri yapılan eserde açılamalar, metin ve dizin bölümleri de yer almakta; ancak yukarıda bahsedilen probleme yönelik bir bölüme yer verilmemektedir. Eserin 1042 satırdan oluştuğu ve 797 farklı kelimeyi sözvarlığında barındırdığı hesaba katıldığında, eser üzerine yeni çalışmalarının yapılmasının gerekliliği ortaya çıkmaktadır. Bu çalışmada Yunusoğlu neşrindeki Eski Uygurca kelimelerin Çincedeki imlası esas alınmak suretiyle denkliklere dayalı bir veri tabanı oluşturulmuş; ardından da bu denklikler esaslı ses olayları tespit edilmiştir. Bu çalışma, işte bu ses olaylarından birini, ünsüz türemesi hadisesini ele almakta ve Türkçe kelimelerin Çincede söylenirken ne tür değişikliklere uğradığını örneklerle göstermektedir. 


\section{TÜRKÇE VERINTILERDE ÜNSÜZ TÜREMESI}

Modern Türk yazı dillerinde Az. samit artımı, Tkm. çekimsiziň artdırılması, Gag. konson(ant) eklemesi, Özb. undóş órtişi, YUyg. üzük tavuşniň qoşulup qelişi, Tat. tartiq östälü, Bşk. tartinqi östäw, Kmk. tutuk awaz koşulmă̆̆, Krç.-Malk. kısık tawuşnu koşuluwu tunakı tawuşnu koşuluwu, Nog. tattıktı̌ kosıluwı, Kzk. dawıssızdıň kosıluwı, Krg. ünsüzdün koşulması, Alt. tuyuk tabıştın kojulan, Hks. ün çohtı̌̆ hozılçatham, Tuv. a'jık eves ünnüňnemejiri nemelde a'jık eves ün şekillerinde adlandırılan; Rusçada pribavleniye soglasnogo ve İngilizcede prothesis olarak karşılanan terim için Türkçede ünsüz türemesi (Gürsoy-Naskali, 1997, s. 81; Korkmaz, 1992, s. 163) ya da öntüreme (İmer vd., 2011, s. 204) ibareleri kullanılır.

Ünsüz türemesi bir kelimenin önses, içses ve sonses konumlarında aslında olmayan bir ünsüzün muhtemelen telaffuzu kolaylaştırmak maksadıyla belirmesi durumu olup, önseste ünsüz türemesiyle ilgili örnek olarak Türkçenin çeşitli tarihi ve çağdaş kollarından ayva > hayva, ır > yır, elbette > helbette, ırak > yırak, igit > yiğit kelimeleri gösterilebilir (Korkmaz, 1992, s. 163; İmer vd., 2011, s. 204).

Ünsüz türemesi kelimedeki konumuna göre üç şekilde görülebilir. Önseste $h, h$ gibi boğumlanma noktaları zayıf olan ünsüzler ile $v, y$ gibi yarı ünlüler; içseste söyleyiş sıkıntısını gidermek için $y$ yarı ünlüsü ile $n$ ünsüzü, sonseste ise $h, m, n, r$ ünsüzleri türeyebilir (Karaağaç, 2010, s. 94-102):

\section{i. Önseste}

a. $y$ - türemesi ıpar > yıpar 'koku', ipek> yipek 'ipek', ıgaç> yıgaç 'ağaç', in-

$>$ yin- 'inmek', irin > yirin 'irin', idiz > yitiz 'yüksek, yüce',

ip > yip 'ip'

b. v- türemesi $u r$ - > vur- 'vurmak'

c. $h$ - türemesi ayva > hayva 'ayva', orada > horda 'orada', ăg $l l>$ hağll 'ağıl', elbet $>$ helbet 'elbette (ağılarda)'

\section{ii. İçseste:}

a. -y- türemes dinle-y-en, eski-y-ince, başla-y-ayım, okulda-y-ım

b. -n- türemes evi-n-e, baba-s-l-n-a

\section{iii.Sonseste:}

a. $-r$ türemesi: kehruba $>$ kehribar

b. $\boldsymbol{n}$ türemesi radyo > radyon

c. $-\boldsymbol{h}$ türemesi peyda $>$ peydah, tali' $>$ talih

d. $-m$ türemes: keşke $>$ keşkem, halbuki $>$ halbukim

Tablo 1. Türkçe kelimelerde görülen ünsüz türemesi örnekleri (Karaağaç 2010: s. 94-102)

Bununla beraber Türkçe bazı kelimeler de başka dillere verintilenirken, bir ihtimal kulak yoluyla alıntılanarak o dilin kendi iç yapısına ve fonetiğine uygun olacak şekilde 
ünsüz türemesine uğrayabilmektedir. Sözgelimi TVS'den tespit edilen pek çok kelime arasından seçilen aşağıdaki örnekler bu durumun evrenselliğini göstermesi bakımından önemlidir. ${ }^{1}$

\begin{tabular}{l}
\hline$a b a>$ Sirpça haba (TVS s. 1) \\
$a c \imath>$ Makedonca haciya (TVS s. 5) \\
$a c ̧ \imath k>$ Sirpça háçik (TVS s. 6) \\
$a d a>$ Arnavutça hadë (TVS s. 7) \\
akıncı > Bulgarca yakıncíya (TVS s. 16) \\
alçak > Bulgarca halçák (TVS s. 23) \\
ana > Makedonca yana, yane (TVS s. \\
31)
\end{tabular}

ark > Bulgarca hark, Sırpça járak (TVS s. 39)

ĕge > Sirpça jége (TVS s. 274)

eksik > Sirpça yéksik (TVS s. 277)

elek > Bulgarca yelék (TVS s. 279)

eski > Farsça kékse (TVS s. 286)

eşek > Arapça yeşek (TVS s. 288)

ılgar > Urduca yalgar (TVS s. 378)

ibrik > Ermenice yíbrík (TVS s. 382)

idikut > Çince yìdūhù (TVS s. 384)

iğde > Rusça cída, Ermenice hide (TVS

s. 385)

iğdiş > Sırpça hidiç (TVS s. 385)

ilik > Sırpça jéljike (TVS s. 390)

imbik > Bulgarca linbik (TVS s. 392)

inak > Çince yĭnà (TVS s. 393)

ocak > Arapça vicak, vīcāk, vucākāt

(TVS s. 646)
oda > Macarca hodály, Romence hodáire,
Sirpça hódaja, Arnavutça hodë, hodhë,
Yunanca nudás (TVS s. 647)omuz >
Bulgarca yemús (TVS s. 652)

onbaşı > Makedonca yonbaşiya (TVS s. 652)

öfke > Bulgarca yufké (TVS s. 661)

ömür > Bulgarca yomyur, Yunanca ğiomúr

(TVS s. 663)

ördek > Arapça vardak, vardakāyī, Bulgarca

yurdék, yurdeçka (TVS s. 664)

örnek > Bulgarca yurnék, Yunanca ğürnéki,

ğiurnéki (TVS s. 664)

öşür > Çince wŭshòu'ěr (TVS s. 665)

uğru > Rusça vor, voryúga, Fince voro (TVS

s. 873)

uğur > Arapça yugur (TVS s. 873)

ukar > Farsça hukar (TVS s. 873)

ulak > Çince wou-lo, Rusça valáh, valáhi

(TVS s. 874)

ulus > Çince $w \bar{u} l \bar{u} s \bar{s}$ (TVS s. 875)

ustura > Macarca kusztora (TVS s. 877)

ücret > Bulgarca yucerét (TVS s. 880)

ülke > Bulgarca yulke (TVS s. 880)

ülker > Bulgarca yulkerét (TVS s. 880)

üst > Bulgarca yusté, Makedonca yust (TVS

s. 881)

Tablo 2. Türkçe verintilerde görülen ünsüz türemesi örnekleri

Listeden anlaşılacağı üzere Türkçeden başka dillere verintilenen bazı kelimelerde, dilden dile farklılık göstermekle beraber, $c, \breve{g}, h, j, k, l, n, w, y$ ünsüzlerinin türeyebildiğ

\footnotetext{
${ }^{1} \mathrm{Bu}$ liste TVS ve başka kaynaklar titiz bir şekilde taranarak genişletilebilir. Amaç, farklı dillere verintilenmiş Türkçe kelimelerdeki ünsüz türemelerine örnekler göstermektir. Ayrıca burada seçilen örnekler sadece ünsüz türemesinin olduğu kısımlarla sınırlıdır. Sözgelimi ocak kelimesi için Arapçada ōcāk, vicak, $\bar{u} c \bar{a} k, v \bar{u} c \bar{a} k, \bar{o} c \bar{a} g$, ivcāg, ōcākāt, ucākāt, vucākāt, ibin ivcāg, vahakhāzi'l-ōcāg kelimeleri kullanılmaktadır. Ancak bu listede sadece ünsüz türemesinin olduğu vicak, vūcāk, vucākāt kelimeleri gösterilmiştir.
} 
görülür. Bu tür türemeler tersine döndürme yöntemiyle Türk dilinin tarihi kayıtlarında geçmeyen, ancak komşu ve yabancı kaynaklarda kayıtlı Türkçe kelimelerin özgün biçimlerini tespit etmede bir ölçüt olarak kullanılabilmesi bakımından önemlidir.

\section{a. Çincenin Ünlüleri Üzerine}

Çin kaynaklarındaki Türkçe kelimeleri yorumlayabilmek için Çincenin ünlü sistemini kısaca tanımak yerinde olacaktır. Çincenin ses sisteminde birleşik ünlüler hariç Çincenin standart ünlülerini karşılayan /a/, /e/, /i/, /o/, /u/ ve /ü/ şeklinde altı temel ünlü bulunmaktadır (Azertürk, 2016, s. 153).

Çincedeki ünlüler Türkçedeki ünlülerle kıyaslandığında, kimi farklılıklar ya da benzerlikler görülmektedir. Sözgelimi /e/, /ə/, / / /, /i/, /u/, /ü/ gibi sesler Türkçe ve Çincede benzer iken (Tuğlu, 2006, s. 36-37), /a/, /o/ gibi sesler Türkçe ve Çincede farklılık gösterebilmektedir. Ayrıca Türkçe /ö/ sesi Çincede, Çince /er/ sesi ise Türkçede bulunmamaktadır (Tuğlu, 2006 s. 42-44).

Çincedeki ünlülerin sınıflandırılmaları teşekkül noktalarına göre Tablo 3'teki, yapısına göre ise Tablo 4'teki şekilde birleştirilerek tablolaştırılabilir:

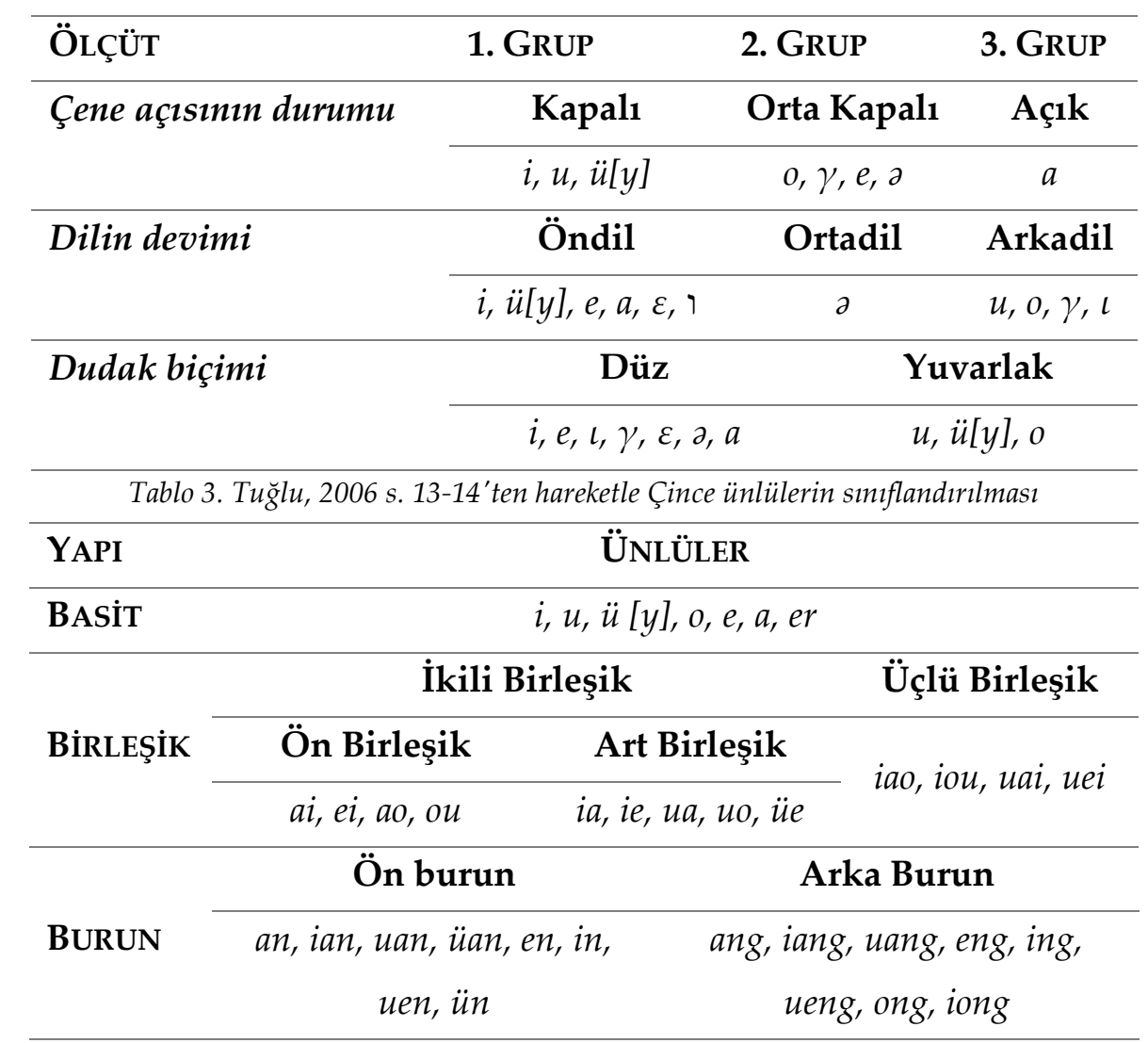

Tablo 4. Tuğlu, 2006, s. 14-26'dan hareketle Çince ünlülerin yapı bakımından sınıflandırılması

Çincede ünlüler kadar, ünlülerin anlam ayırt edici tonları da önem arz etmektedir. Pekin Çincesinde yüksek düzey ton $\left(^{(}\right)$, yükselen ton ('), alçalan-yükselen ton (`), alçalan ton (') olmak üzere dört ton bulunmaktadır (Pulleyblank, 1995, s. 6-7, Finegan, 2008, s. 92 ve Eker, 2010, s. 316). 


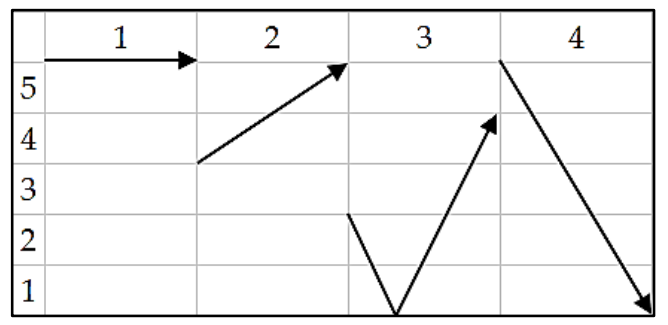

Şekil 1. Mandarin Çincesinin Tonları (CLC s. 38)

Bir örnek vermek gerekirse, Çincede /a/ ünlüsünün $\bar{a}$, á, à ve $\breve{a}$ olmak üzere dört tonu bulunmakta, tonsuz a (nötr) biçimi de sayılırsa buna bağlı olarak beş farklı anlamı göstermektedir:

\begin{tabular}{|c|c|c|c|c|c|}
\hline & YÜKSEK & $\begin{array}{c}\text { YÜKSELE } \\
\mathbf{N}\end{array}$ & ALÇALAN & $\begin{array}{l}\text { ALÇALAN- } \\
\text { YÜKSELEN }\end{array}$ & NÖTR \\
\hline Pinyin & $\bar{a}$ & $a ́$ & $\grave{a}$ & $\breve{a}$ & $a$ \\
\hline Orijinal & 妈 & 麻 & 马 & 咒 & 吗 \\
\hline MCD V & $m \bar{a}$ & má & $m \breve{a}$ & mà & $m a$ \\
\hline IPA 69 & $m a 1$ & $m a^{\prime}$ & $m a$, & $m a \backslash$ & $m a$ \\
\hline IPA 69 & má & $m \hat{a}$ & $m \vec{a}$ & $m i \bar{a}$ & $m a$ \\
\hline Anlam & 'anne' & 'kenevir' & 'at' & 'lanet' & 'soru eki' \\
\hline
\end{tabular}

Çincedeki önseste konumlanan tonluların dağılımı orta hacimli bir sözlük olan MCD'den hareketle şöyle gösterilebilir:

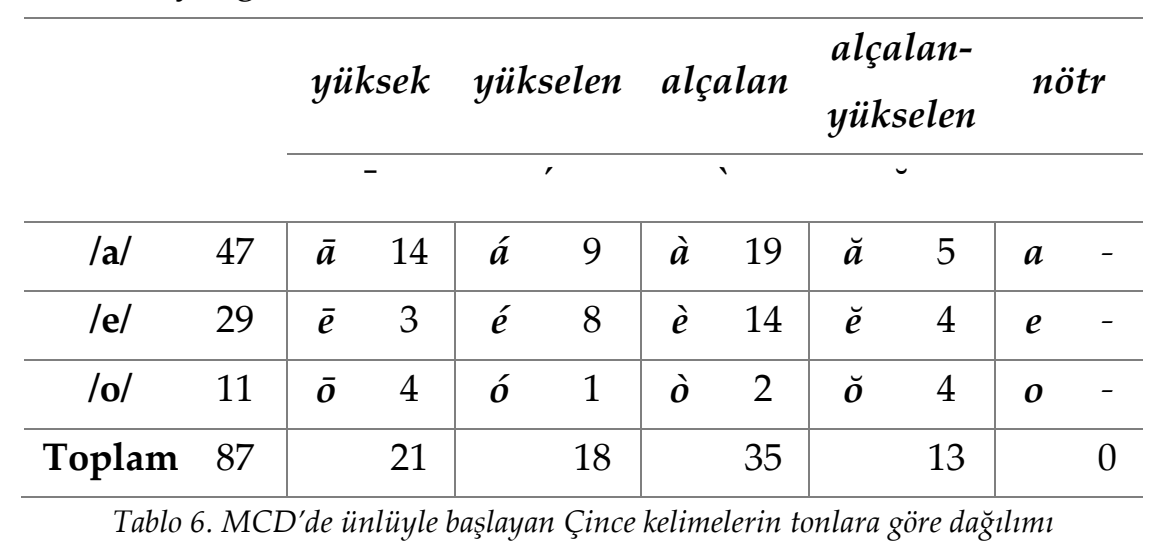

Tablo 6'dan anlaşılacağı üzere, tonsuz yani nötr ünlülerle Çince kelimeler başlamamaktadır. Bununla beraber Türkçeyle kıyaslandığında Çince kelimelerin /1/, /i/, /ö/, /u/ ve /ü/ ünlüleriyle de başlamadığı görülür. Bu durumda 'Çince, ünlüyle başlayan kelimeleri alıntılandığında nasıl davranmaktadır?' sorusunu sormak gerekecektir. Dünyada sık kullanılan dillerle ilişkiler, 21. yüzyılın gelişmelerine bağlı olarak hızla arttığına göre, Çincede de pek çok alıntı kelimenin bulunması gerekecektir. 


\begin{tabular}{|c|c|c|c|c|c|}
\hline Sira & Dil & $\begin{array}{c}\text { Konuşur Sayısı } \\
\text { (milyon) }\end{array}$ & Sira & Dil & $\begin{array}{c}\text { Konuşur } \\
\text { Sayısı } \\
\text { (milyon) }\end{array}$ \\
\hline 1 & Çince & 1311 & 14 & Türkçe & 79,4 \\
\hline 2 & İspanyolca & 460 & 15 & Korece & 77,3 \\
\hline 3 & İngilizce & 379 & 16 & Fransizca & 77,2 \\
\hline 4 & Hintçe & 341 & 17 & Almanca & 76,1 \\
\hline 5 & Arapça & 319 & 18 & Vietnamca & 76 \\
\hline 6 & Bengalce & 228 & 19 & Tamilce & 75 \\
\hline 7 & Portekizce & 221 & 20 & Urduca & 68,6 \\
\hline 8 & Rusça & 154 & 21 & Cava Dili & 68,3 \\
\hline 9 & Japonca & 128 & 22 & İtalyanca & 64,8 \\
\hline 10 & $\begin{array}{l}\text { Lahnda Dil } \\
\text { i }\end{array}$ & 119 & 23 & Farsça & 61,8 \\
\hline \multirow[t]{2}{*}{11} & Marathi Dil & & 24 & & \\
\hline & $\mathrm{i}$ & 83,1 & & Gujarati Dili & 56,4 \\
\hline \multirow[t]{2}{*}{12} & & & 25 & Bhojpuri & \\
\hline & Telugu Dili & 82 & & Dili & 52,2 \\
\hline 13 & Malayca & 80,3 & Topla & & 3427,5 \\
\hline
\end{tabular}

Tablo 7'ye göre dünyada yaklaşık üç buçuk milyar insan bu 25 dilden birini konuşmaktadır. Çince dünyada en fazla konuşuru olan dildir. Onu İspanyolca ve İngilizce takip etmektedir. Hem Türkçeye hem de Çinceye kelime vermesi bakımından İngilizce örnekleminde birkaç örneğe bakmak, Çincenin ünlüyle başlayan alıntıları nasıl değerlendirdiğini görmek için ipuçları verecektir.

\begin{tabular}{lllll}
\hline İngilizce & Türkçe & $\begin{array}{l}\text { Çince } \\
\text { Yazım }\end{array}$ & $\begin{array}{l}\text { Çince } \\
\text { Pinyin }\end{array}$ & Kaynak \\
\hline Arizona & Arizona & 亚利桑那 & yàlìsāngnà & SML 277 \\
\hline aspirin & aspirin & 阿斯匹林 & āsīpǐlín & SML 277 \\
\hline email & e-mail & 伊妹儿 & yī-mèi-ér & SML 286 \\
\hline eureca & Evreka & 尤里卡 & yóu lǐ kă & SML 287 \\
& 'buldum' & & & \\
\hline Intel & İntel & 英特尔 & yīngtèěr & SML 291 \\
\hline index & indeks & 引得 & y̌̌ndé & SML 291 \\
\hline italy & İtalya & 意大利 & yìdàlì & SML 292 \\
\hline
\end{tabular}




\begin{tabular}{lllll}
\hline olympic & olimpik & 奥林匹克 & àolínpǐkè & SML 299 \\
\hline opium & afyon & 阿片 & yāpiàn & SML 299 \\
\hline oscar & oskar & 奥斯卡 & àosīkă & SML 299 \\
\hline UFO & ufo & 幽浮 & yōu fú & SML 308 \\
\hline ultimatum & ultimatom & 哀的美敦 & āidìměidūn & SML 308 \\
\hline utopia & ütopya & 乌托邦 & wūtuōbāng & SML 308 \\
\hline \multicolumn{2}{c}{ Tablo 8. İngilizceden kelimelerin Türkçe ve Çincedeki görünümüne SML'den örnekler }
\end{tabular}

Tablo 8'deki verilerden hareketle Çincenin, İngilizceden alıntılanan ve ünlüyle başlayan kelimelerin bazılarında önseste /y/, bazılarında ise /w/ sesini, Çincenin söyleyiş yapısına uygun olarak türettiği gözlenmektedir.

Türk dilinin tarihi kaynaklarında geçmeyen ancak Çince kaynaklarda rastlanan Türkçe kelimelerin özgün biçimlerini tespit etmede Çincenin bu özelliği bir ölçüt olarak kullanılabilir. Çince kaynaklarda parça parça kısmen ve sistemsiz olarak geçen Türkçe kelimelerden ziyade, bir metnin sistemli ve Çince-Türkçe bakışımlı olarak işlendiği UygurcaÇince İdikut Sözlüğ̈̈ isimli eser üzerinde Türkçe kelimelerin özgün biçimlerine yönelik tespitlerde bulunmak daha verimli olacaktır. O sebeple bu çalışmada Yunusoğlu tarafından yayınlanan Uygurca-Çince İdikut Sözlü̆̆̈̈ metni esas alınmıştır. Çevriyazı sistemi bakımından, Yunusoğlu'na bağlı kalınan² bu çalışmada elde edilen verilere göre Eski Uygurcada önseste /w/ ve /y/; içseste hece başında /w/ ve /ç/; içseste hece sonunda /n/ ünsüzlerinin türediği, sonseste ise bir ünsüz türemesine rastlanmadığ1 gözlenmiştir

\footnotetext{
2 Yunusoğlu, çalışmasında Mathews 1975'teki sistemin esas alındığından bahsetmektedir. Bu makalede de Yunusoğlu'ndan hareketle dolaylı olarak Mathews 1975'teki sisteme bağlı kalınmıştır. Yunusoğlu, çalışmasında bu sistemin nasıl olduğundan bahsetmez (Yunusoğlu 2002: X). 1877-1970 yılları arasında yaşayan Robert Henry Mathews, esasında Frederick William Baller'in An analytical Chinese-English dictionary: compiled for the China Inland Mission (1900) başlıklı sözlügüunü geliştirmek için yola çıkmış ve 1931'de Mathews' Chinese-English Dictionary adlı sözlügüüü hazırlamıştır. 1943 ve 1975'te revize edilen sözlük'te Herbert A. Giles tarafından hazırlanan ve ilk baskısı 1892'de yapılan Chinese-English Dictionary'den de yararlandığı görülür (RHM). Mathews 1975'te kullanılan sistem esasında günümüzde kullanılan Pinyin sistemine benzemektedir. Bir iki örnek vermek gerekirse Mathews Eski Uygurcada 'nehir' anlamına gelen ögüz kelimesi karşılığında gösterdiği Çince 河 kelimesini he şeklinde latinize etmiş olup aynı kelime Pinyin sisteminde hé şeklindedir. Eski Uygurca ta 'dağ' karşılığında Çince 山 kelimesinin latinize biçimini Mathews shan olarak gösterirken, Pinyin'de bu kelime shān olarak gösterilmektedir.
} 


\section{VERİ [88]}

\section{a. Önseste Ünsüz Türemesi [84]}

\section{i.w- Türemesi [67]}

1. o- > wu- [16]

obur '? '3', obur subur4 'arka arkaya, hiç ara vermeden, sürekli' UÇİS s. $168 \rightarrow$ obur $>$ wu-pu-êrh [P781]

od $\gamma$ uraq 'mutlak, muhakkak, kesin; net, kuvvetli' UÇİS s. $168 \rightarrow$ otyaraq $>$ wuha-la [P767]

olar 'onlar' UÇİS s. $168 \rightarrow$ olar $>$ wu-la-êrh [P334]

olur- 'oturmak, oturtmak' UÇiS s. $168 \rightarrow$ olur $>$ wu-lu-êrh [P607], olurup $>$ wu-lulu [P734]

oma $<$ Mo. omuğ 'soy, soyad; aile' UÇi̇s s. $168 \rightarrow$ omaq > wu-ma [P649]

omo $\gamma$ 'sahip, patron' UÇİS s. $168 \rightarrow$ omo $\gamma>$ wu-mo [P303]

oq1- 'okumak, öğrenmek' UÇiSs s. $168 \rightarrow$ oqı > wu-hei [P527, P532]

oq1t- 'okutmak, öğretmek, ezberletmek' UÇİS s. $168 \rightarrow$ oqıtu > wu-hei-tou [P855]

ordu 'saray, orda' UÇİS s. $168 \rightarrow$ ordu $>$ wu-êrh-tou [P381]

ornuq < Mo. 'yatak, kalacak yer, yer' UÇi̇s s. $168 \rightarrow$ ornuq > wu-êrh-na [P401]

otaz 'yaban sığırı, gergedan' UÇi̇s s. $168 \rightarrow$ otaz > wu-ta-ssŭ [P216]

otçı 'tabip, hekim' UÇİS s. $168 \rightarrow$ otçi > wu-chê [P316]

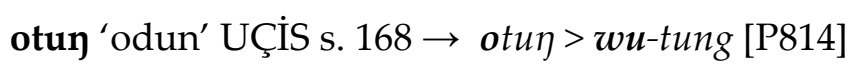

otuz 'otuz' UÇİS s. $168 \rightarrow$ otuz $>$ wu-tou-ssŭ [P579]

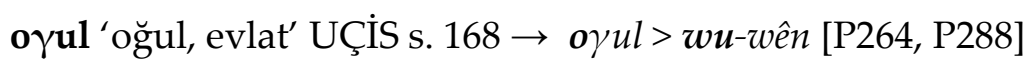

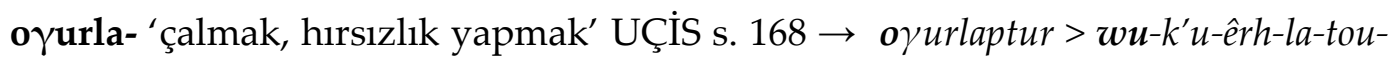
êrh [P817]

2. $o->$ wo- [1]

onunç 'onuncu'UÇİS s. $168 \rightarrow$ onunç > wo-nan-ch'ê [P120]

3. $o->w a-[3]$

on 'on' UÇİS s. $168 \rightarrow$ on > wan [P576, P577, P584, P585, P596]

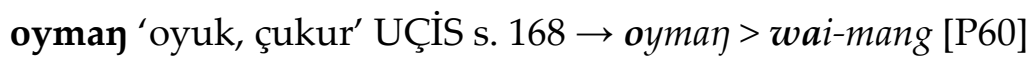

oyna- 'oynamak, oyun oynamak' UÇİS s. $168 \rightarrow$ oyna > wai-na [P694]

4. $\quad o->w \hat{e}-[3]$

on 'sağ; doğru' UÇİS s. $168 \rightarrow$ o $\eta>$ wêng [P538]

on < Çin. wang 'han, kral' UÇİS s. $168 \rightarrow$ o $\eta>$ wêng [P971]

\footnotetext{
${ }^{3}$ Metin kısmında ikileme şeklinde geçen kelime için Çince karşılık olarak 'peşpeşe' 'peş peşe' anlamına gelen 陸續 [lùxù] kelimeleri kullanılmıştır (MDBG).

4 sobur kelimesi metnin dizininde sobur (UÇİS 168), metnin içinde P781'de subur (UÇís 109) şeklinde gösterilmiştir.
} 
Yunusoğlu'nun çalışmasında da zaten ayrı başlık halinde ele alınmıştır.

onay 'kolay' UÇİS s. $168 \rightarrow$ oyay $>$ wêng-kai [P634]

\section{5. $\quad \ddot{o}->w u-[8]$}

öçül- 'silinmek, yok edilmek, kökü kurutulmak' UÇİS s. $169 \rightarrow$ oçül $>$ wu-shuo (wu-ch'uan) [P811]

öçi- < Mo. 'haber vermek, bilgi vermek, rapor sunmak (hakana, hükümdara)' UÇİS s. $169 \rightarrow \ddot{o} c ̧ i p>$ wu-ch'ê [P635, P793]

ögüz 'irmak, dere' UÇİS s. $169 \rightarrow$ ögüz > wu-k'u-ssŭ [P51]

ölür- 'öldürmek' UÇİS s. $169 \rightarrow$ ölürüp (ölüp) > wu-lu (wu-lu-lu) [P844]

ördäk 'ördek' UÇİS s. $169 \rightarrow$ ördäk > wu-êrh-tê [P208]

öz 'öz, kendi; şahıs; vücut, beden; yaşam, hayat (can)' UÇi̇s s. $169 \rightarrow \ddot{\boldsymbol{o} z}$-i $>\boldsymbol{w} \boldsymbol{u}$ ssŭ [P733], özüng > wu-sung [P676]

örtün- 'örtünmek, kapanmak' UÇİS s. $169 \rightarrow$ örtünmiş > wu-êrh-tun-mi-shih [P653]

ötkür- 'geçirmek, bir şeyi bir şeyin içinden geçirmek, göndermek' UÇİS s. $169 \rightarrow$ ötkürmiş > wu-k'u-êrh-mi-shih [H1004]

6. $\quad \ddot{o}->w a-[1]$

öl '1slak' UÇíS s. $169 \rightarrow \ddot{o} l>$ wan [P26]

7. $\ddot{o}->w \hat{e}-[3]$

öydün 'doğu, doğuda, önde; önceden' UÇİS s. $169 \rightarrow$ öydün > wêng-tun [P533]

öngärä- 'geçmek (önünden)' UÇIS s. $169 \rightarrow$ öygäräp > wêng-k'ê-la [H1022]

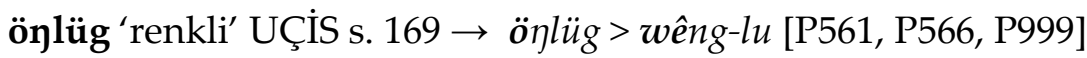

8. $u->w u-[23]$

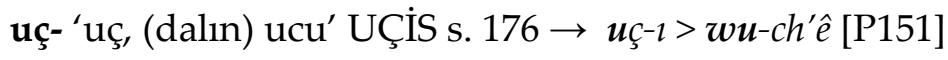

uça 'sırt, arka, omuz' UÇi̇s s. $176 \rightarrow \boldsymbol{u c ̧ a ~}>\boldsymbol{w} \boldsymbol{u}$-ch'a [P370]

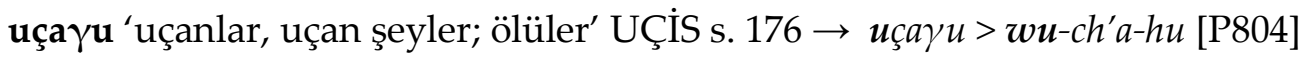

uçuq 'çorap' UÇİS s. $176 \rightarrow$ uçuq > wu-shuo [P448]

ud 'inek, sığır' UÇi̇s s. $176 \rightarrow u d>w u$ [P190]

ud- 'takip etmek, izlemek, devam etmek' UÇiS s. $176 \rightarrow \boldsymbol{u d u p}>\boldsymbol{w} \boldsymbol{u}$-t'u [P713, P951]

udu $\gamma$ 'sayg1, hürmet, ihtiram' UÇİS s. $176 \rightarrow \boldsymbol{u d u \gamma}>\boldsymbol{w} \boldsymbol{u}$-t'o [P691]

ula- 'kavuşmak; ulamak, bağlamak, uzatmak' UÇİS s. $176 \rightarrow$ ulatı $>$ wu-la-tê [P745]

ulam 'ek, devam eden, devami; daimi, eksiksiz' UÇíS s. $176 \rightarrow$ ulam > wu-lan [P952]

ulayatı < Fa. vila:yat ‘Batı Bölgesi' UÇİS s. $176 \rightarrow$ ulayatı > wu-la-ya-tê [P985] 


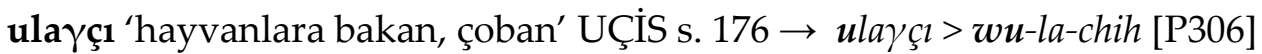

ulus < Mo. ulus 'ulus, devlet' UÇİS s. $176 \rightarrow$ ulus > wu-lu-ssŭ [P56, P971, P972]

ulu $\gamma$ ‘büyük, ulu, ulular' UÇİS s. $176 \rightarrow$ ulu $\gamma>$ wu-lu [H1008, P251, P256]

uqar 'leylek, turna' UÇİS s. $176 \rightarrow$ uqar $>$ wu-ha-êrh [P201]

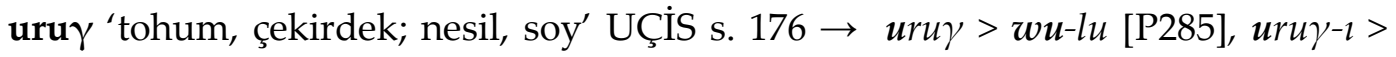
wu-lu-hei [P152]

utlı 'ödül, mükafât, karşılık; iyilik, fazilet; teşekkür, minnettarlık' UÇíS s. $176 \rightarrow$ $u t l ı>w u-l i[\mathrm{P} 949]$

utlıçı 'iyilik yapan, iyilik sahibi, teşekkür edilecek adam' UÇİS s. $176 \rightarrow$ uthıçı > wu-li-chih [P309]

uz 'usta, mesleğini iyi bilen, uzman' UÇİS s. $176 \rightarrow \boldsymbol{u} z>\boldsymbol{w} \boldsymbol{u}$-ssŭ [P318, P827]

uzat- 'uğurlamak, yolculuk etmek, götürmek' UÇi̇S s. $176 \rightarrow$ uzat > wu-sa [P714]

uzat- 'uzatmak; sunmak, vermek' UÇíS s. $176 \rightarrow$ uzatıp > wu-sa-t'ê [P998]

uzat- 'göndermek ${ }^{5 \prime}$ UÇİS s. $176 \rightarrow$ uzatıp > wu-san-t'ê [H1024]

uzun 'uzun' UÇi̇s s. $176 \rightarrow$ uzun > wu-tsun [P647]

uүrayu 'özel, mahsus, kişisel' UÇi̇S s. $176 \rightarrow$ uүrayu > wu-la-yü [P869]

9. $\quad \ddot{u}->w u-[9]$

ükär 'Ülker Yıldızı' UÇİS s. $177 \rightarrow \ddot{u} k a ̈ r>w u$-ke-êrh [P41]

ürgülçi < Mo. ürgülji ‘sürekli, durmaksızın, devamlı, kesiksiz' UÇi̇S s. $177 \rightarrow$ ürgülçi > wu-êrh-kun-chih [H1015]

ürkäç 'ebedi, ömür boyu, uzun zaman' UÇİS s. $177 \rightarrow$ ürkäç > wu-êrh-kê-ch'ih [H1016]

üşik < ? $^{6}$ 'hece, harf, alfabe, yazı; yazı yazmak' UÇİS s. $177 \rightarrow$ ussik $>$ wu-shih [P528]

üzä ‘her zaman, sürekli, devamlı, sabit’ UÇi̇s s. $177 \rightarrow \ddot{u} z-\ddot{a}>\boldsymbol{w u}$-sa [P636]

üzịt 'cin, şeytan, ruh' UÇİS s. $177 \rightarrow$ üzit > wu-hsi [P272]

üzük 'yazı, harf, hece, ses' UÇİS s. $177 \rightarrow$ üzük > wu-tsu [P776]

üzül- 'kesik, üzülmek' UÇiS s. $177 \rightarrow$ üzülmäz > wu-suan-ma-ssŭ [H1020]

üzüm 'üzüm' UÇİS s. $177 \rightarrow$ üzüm > wu-tsun [P170]

\section{ii.y- Türemesi [17]}

1. $1>y i-[1]$

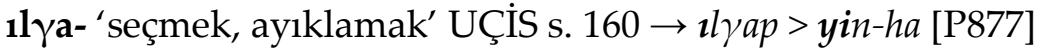

\footnotetext{
${ }^{5}$ Dizinde bu veriye yer verilmemiştir, ancak metinde H1024'te Çincede 'göndermek' (MCD 996) anlamına gelen 打發 $[t a-f a]$ karşılı̆̆ verilmektedir.

${ }^{6}$ Kelimenin metindeki karşılığında Çincede 'harf, sembol, karakter, kelime' anlamına gelen 字 [zì] ibaresi geçmektedir (MDBG).
} 


\section{2. $i>y i-[9]$}

il 'il, devlet; halk, toplum' UÇi̇s s. $160 \rightarrow$ il > yin [P317, P658]

ilçi 'elçi, temsilci' UÇi̇s s. $160 \rightarrow$ ilçi > yin-chih [P308]

ilsän- 'teslim olmak, boyun eğmek' UÇİS s. $160 \rightarrow$ ilsänip > yin-sa-ni [P768]

inç 'sakin, huzur, rahat; sessiz; barış, sulh' UÇİS s. $160 \rightarrow$ inç > yin-ch'ê [P764], inç täg > yin-ch'ê-tê [P863]

inçip 'fakat, ancak, yalnız, ama; bunun üzerine' UÇi̇s s. $160 \rightarrow$ inçip > yin-ch'ê [P720]

inçkä 'ince, zarif, yufka' UÇİS s. $160 \rightarrow$ inçkä > yin-ch'ê- $k^{\prime} \hat{e}$ [P946]

inçkä 'bilge, aydın; Konfüçyüs'ün talebeleri' UÇi̇S s. $160 \rightarrow$ inçkä > ying-ch'ê- $k^{\prime} \hat{e}$ [P274]

inçläntür- 'sakinleştirmek, rahatlatmak' UÇİS s. $160 \rightarrow$ inçläntürmiş > ying-ch' $\hat{e}$ lan-tou-êrh-mi-shih [P656]

in- '?7 (kaybolan1) aramak, araştırmak' UÇİS s. $160 \rightarrow$ indi > ying-tê [P695]

3. $\ddot{o}>y \ddot{u}-[2]$

öd 'vakit, zaman, an, mevsim' UÇiS s. $169 \rightarrow \ddot{o} d>$ yü [P86, P125]

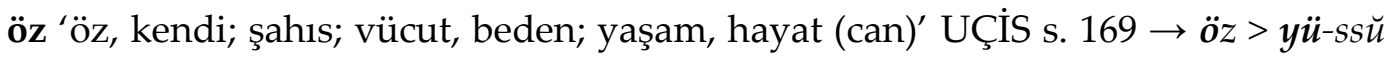
[P747]

\section{4. $\ddot{u}>y u-[1]$}

ünçü < Çin. chên-chu 'inci' UÇi̇S s. $177 \rightarrow$ ünçü > yung-chu [P476]

5. $\ddot{u}>y \ddot{u}-[4]$

üç 'üç' UÇİS s. $177 \rightarrow$ üç > yü-ch'ê [P569]

üçünç 'üçüncü' UÇi̇s s. $177 \rightarrow$ üçünç> yü-shun-ch'ê [P113]

üstün 'üst, yukarı, üst taraf' UÇİS s. $177 \rightarrow$ üstün > yü-ssŭ-tun [P541]

üstünki 'yukarıdaki, üstteki; en üsttekiler, kral, hükmedenler, yöneticiler' UÇi̇s s. $177 \rightarrow$ üstünki> yü-ssŭ-tun-chi [P292]

b. İçseste Ünsüz Türemesi [4]

\section{i.Hece Başında [3]}

1. /w- Türemesi [1]

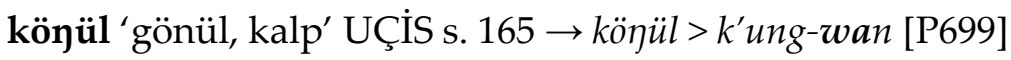

\section{2. /ç- Türemesi [2]}

mäni ‘neşe, sevinç' UÇíS s. $167 \rightarrow$ mäni > mang-chi [P602]

mänilä- 'sevinmek, eğlenmek, keyiflenmek' UÇİS s. $167 \rightarrow$ mäyiläyür > mang-chila-yü-êrh [P766]

\footnotetext{
${ }^{7}$ Kelimenin metindeki karşılığında Çincede 'aramak' anlamına gelen 尋㝟 [xúnmì] ibaresi geçmektedir (MDBG).
} 


\section{ii.Hece Sonunda [1]}

\section{1. -n/ Türemesi}

sa $\gamma$ urt 'karışık? çeşitli (kelimeler)?' UÇiS s. $177 \rightarrow$ saqurt > san-k'u [P532]

\section{DEĞERLENDİRMELER, TESPITTLER VE SONUÇ}

a. UÇİS'ten elde edilen veri tasnif edildiğinde ses olaylarının hemen hemen tümüne örnek bulunabilmektedir. Bu çalışmanın sınırlılığı ile ilgili olarak ünsüz türemesi örnekleri tarandığında 90'a yakın veriyle karşılaşılmaktadır.

b. UÇİS'te ünsüz türemesi önseste ve içseste tanıklanmaktadır. Sonseste tanıklanan bir ünsüz düşmesi örneği yoktur.

c. UÇİS'te önseste ünsüz türemesi olayıyla ilgili 84 veriye ulaşılmaktadır. Bu veriler /w/ ve /y/ ünsüzlerinin türediği gruplar olmak üzere ikiye ayrılarak değerlendirilebilir.

d. UÇİS'te önseste /w/ türemesinin 67 örneği bulunmaktadır. /w/ türemesi örneklerinin tamamında önseste yuvarlak ünsüzlerin bulunması dikkate değerdir. En sık /o/ ve /u/ seslerinden önce /w/ ünsüzünün türediği görülmektedir.

e. /o/ sesiyle başlayan 23 , /u/ sesiyle başlayan 23 , /ö/ sesiyle başlayan 12 ve /ü/ sesiyle başlayan 9 kelimede, önseste /w/ türemesi görülmektedir.

f.Önseste /w/ türemesi görülen 67 kelimeden 56'sında /w/ sesinin yanındaki ünsüz olarak /u/ sesi yer alırken, 6 kelimede /ê/, 4 kelimede /a/ ve 1 kelimede /o/ olmaktadır.

g. UÇİS'te önseste /y/ türemesinin 17 örneği bulunmaktadır. /y/ türemesi örneklerinin 16'sında ince, 1'inde kalın; 15'inde dar, 2'sinde geniş önses ünlüsüne rastlanmaktadır. Bir başka ifadeyle önseste /y/ ünsüzünün türemesi görülen örneklerin yaklaşık olarak \%90'inda dar ve ince önses ünlüsü görülmektedir. En sık /i/ ve /ü/ seslerinden önce /y/ ünsüzünün türediği görülmektedir.

h. /i/ sesiyle başlayan 9, /ü/ sesiyle başlayan 5, /ö/ sesiyle başlayan 2 ve /1/ sesiyle başlayan 1 kelimede, önseste /y/ türemesi görülmektedir.

i.Önseste /y/ türemesi görülen 17 kelimeden 10'unda /y/ sesinin yanındaki ünsüz olarak /i/ sesi yer alırken, 6 kelimede /ü/ ve 1 kelimede /u/ olmaktadır.

j. UÇİS'te içseste ünsüz türemesi olayıyla ilgili 4 veriye ulaşılmaktadır. Bu verilerden üçü içses hece başında, biri içses hece sonunda görülmektedir.

k. İçses hece başında /ç/ ve /w/ ünsüzlerinin türediği görülmektedir. /ç/ sesi biri türev olmak üzere 2 ve /w/ sesi 1 kelimede olmak üzere toplam 3 kelime içses hece başında ünsüz türemesine rastlanmaktadır. Her iki ses türemesinin görüldüğü toplam üç örnekte türemenin olduğu konumda /n/ sesinin yer alması dikkat çekmektedir. 


\begin{tabular}{|c|c|c|c|}
\hline Eski Uygurca Orijinal Biçim & köyül & $k \ddot{o}$ & yül \\
\hline Çince Karakterlerle & $k^{\prime} u n g-w a n$ & $k^{\prime} u n g$ & wan \\
\hline \multicolumn{4}{|c|}{ Tablo 9. Eski Uygurca könül kelimesinin Çince yazımı } \\
\hline Eski Uygurca Orijinal Biçim & $m \ddot{y} y i$ & $m \ddot{a}$ & $y i$ \\
\hline Çince Karakterlerle & mang-chi & mang & chi \\
\hline Eski Uygurca Orijinal Biçim & mänilä- & $m \ddot{a}$ & yilä- \\
\hline Çince Karakterlerle & mang-chi & mang & chila- \\
\hline
\end{tabular}

1. Eski Uygurca kelimelerin Çince karakterlerle yazımında tespit edilen ünsüz türemeleri aşağıdaki şekilde tablolaştırılabilir.

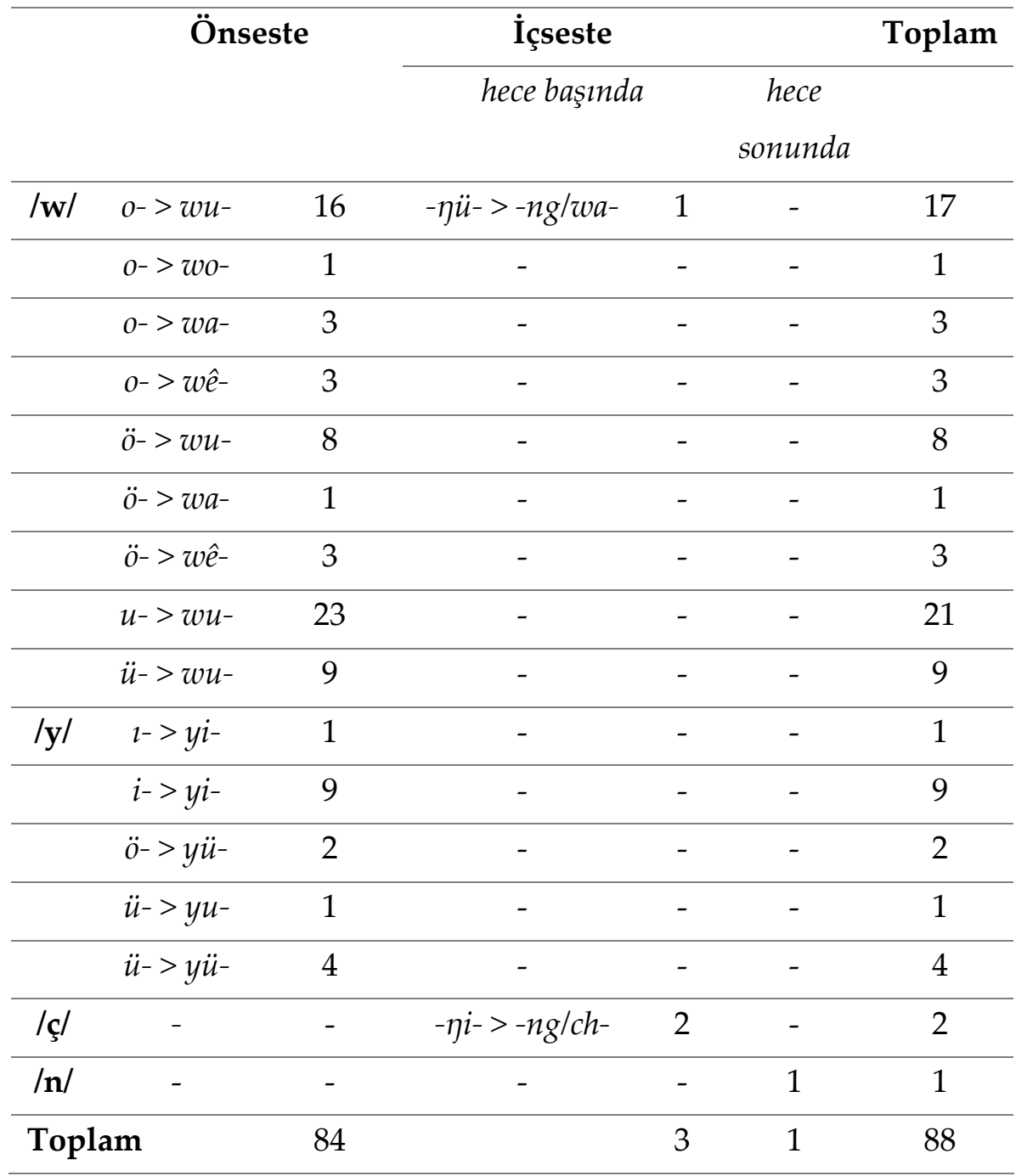

Tablo 11.Eski Uygurca kelimelerin Çince yazımlarında görülen ünsüz türemeleri

m. Tablo 11'e göre, Çincenin söyleyiş ve yazım özelliklerine bağlı olarak önseste yalnızca /w/ ve /y/ sesleri türemekte; en sık önseste ünsüz türemelerine rastlanmakta, en sık türeyen ünsüzün /w/ olduğu görülmekte ve /ç/ ve /n/ ünsüzleri yalnızca içseste hece sonunda türemektedir. 
n. Sonuç olarak bu ses türemeleri, Eski Türkçe kelimelerin Çin kaynaklarından çözümlenmesinde kullanılacak metotlardan biri olarak yer alabilir.

o. Çalışmada elde edilen verilere göre Eski Uygurcada önseste /w/ ve /y/; içseste hece başında /w/ ve /ç/; içseste hece sonunda /n/ ünsüzleri türemektedir. Bir başka ifadeyle Eski Uygurca kelimelerdeki önses /o/ ünlüsünün bulunduğu 23 ve /u/ ünlüsünün bulunduğu 21 veride önce /w/; /1/ ünlüsünün bulunduğu 1 ve /i/ ünlüsünün bulunduğu 9 veride /y/; /ö/ ünlüsü bulunan 14 verinin 12 'sinde /w/ ve 2 'sinde /y/; /ü/ ünlüsüyle başlayan 14 verinin 9'unda /w/ ve 5'inde /y/ ünsüzü türemektedir.

p. Bu tablo Çince imlayla yazılmış Türkçe kelimelerin orijinal biçimlerine ulaşmakta yardımcı olacak veriler sunmaktadır.

\section{KAYNAKÇA}

Azertürk, Semine İmge (2016). 'Ses Bilgisi ve Öğretimi'. Çin Dili (Ed.: Gürhan Kırilen). Ankara: Gece Kitaplı̆̆ı, s. 147-168.

CLC = Poupard, Duncan (2012). Collins Chinese Language and Culture. Glasgow: Harper Collins Publishing.

Eker, Süer (2010). ‘Ünlülerin Temel Özellikleri Üzerine Birkaç Not', Turkish Studies, 5/4: 305320.

Fidan, Giray (2011a). Çin Dili ve Çince Dilbilgisi. (1. Basım). Ankara: Efil Yayınevi.

Fidan, Giray (2011b). Kanuni Devrinde Çin'de Osmanlı Tüfeği ve Osmanlılar. (1. Basım). İstanbul: Yeditepe Yayınevi.

Finegan, Edward (2008). Language and It's Structure and Use. Boston: Thomson Wadsworth.

Gürsoy-Naskali, Emine (1997). Türk Dünyası Gramer Terimleri Sözlüğ̈̈. Ankara: Türk Dil Kurumu Yayınları.

$\mathrm{IPA}=$ “Uluslararası Fonetik Alfabe-II" (Çev. Çetin Pekacar - Figen Güner Dilek). Dil Araştırmaları, 5: 67-86.

İmer, Kamile, Kocaman, Ahmet ve Sumru Özsoy (2011). Dilbilim Sözlüğ̈̈. İstanbul: Boğaziçi Üniversitesi Yayınları.

Karaağaç, Günay (2010). Türkçenin Ses Bilgisi. İstanbul: Kesit Yayınları.

Korkmaz, Zeynep (1992). Gramer Terimleri Sözlüğ̈̈̈. Ankara: Türk Dil Kurumu Yayınları.

Mathews, R. H. (1975). Chinese-English Dictionary. Cambridge - Massachusetts: Harvard University Press.

MCD = Beattie, Susie vd. (2016). Collins Mandarin Chinese Dictionary. Glasgow: Harper Collins Publishing.

MDBG = https://www.mdbg.net/chinese/dictionary?page=worddict\&wdrst=1\&wdqtm= 0\&wdqcham=1\&wdqt=\%E5\%B0\%8B\%E8\%A6\%93 (Erişim Tarihi: 15.05.2019). 
Pulleyblank, Edwin G. (1995). Outline of Classical Chinese Grammar. Vancouer: UBC Press.

RHM = Robert Henry Mathews (http://www.wikizero.biz/index.php?q=aHR0cHM6Ly 9lbi53aWtpcGVkaWEub3JnL3dpa2kvUm9iZXJ0X0hlbnJ5X01hdGhld3M, Erişim Tarihi 14.05.2019).

SML = Kim, Tae Eun (2012). A Study of Mandarin Loanwords: Lexical Stratification, Adaptation and Factors. PhD Thesis. University of Wisconsin-Madison.

Tuğlu, Simay Erden (2006). Türkçe ve Çincenin Ses Yapıları Açısından Karşılaştırılması. Yüksek Lisans Tezi. Ankara: Ankara Üniversitesi Sosyal Bilimler Enstitüsü Doğu Dilleri ve Edebiyatları (Sinoloji) Anabilim Dalı.

TVS = Karaağaç, Günay (2010). Türkçe Verintiler Sözlü̈̆̈̈̈. Ankara: Türk Dil Kurumu Yayınları. UÇİS = Yunusoğlu, Mağfiret Kemal (2012). Uygurca-Çince İdikut Sözlüğ̈̈. Ankara: Türk Dil Kurumu Yayınları. 